\title{
Improvement of Dystrophic Muscle Fragility by Short-Term Voluntary Exercise through Activation of Calcineurin Pathway in $m d x$ Mice
}

\author{
Clement Delacroix, ${ }^{*}$ Janek Hyzewicz, ${ }^{\dagger}$ Megane Lemaitre, ${ }^{*}$ Bertrand Friguet, ${ }^{\dagger}$ Zhenlin Li, ${ }^{\dagger}$ Arnaud Klein, ${ }^{*}$ Denis Furling, ${ }^{*}$ \\ Onnik Agbulut, ${ }^{\dagger}$ and Arnaud Ferry ${ }^{* \sharp}$
}

\begin{abstract}
From the Research Center in Myology, * Association Institute of Myology, Sorbonne University, INSERM, UMRS974, Paris; Biological Adaptation and Aging, ${ }^{\dagger}$ Institute of Biology Paris-Seine, UMR CNRS 8256, INSERM ERL U1164, Sorbonne University, Paris; and Paris Descartes University, ${ }^{\ddagger}$ Sorbonne Paris Cité, Paris, France
\end{abstract}

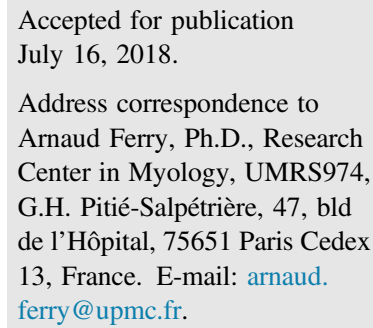

\begin{abstract}
Dystrophin deficiency in $m d x$ mice, a model for Duchenne muscular dystrophy, leads to muscle weakness revealed by a reduced specific maximal force as well as fragility (ie, higher susceptibility to contractioninduced injury, as shown by a greater force decrease after lengthening contractions). Both symptoms could be improved with dystrophin restoration-based therapies and long-term (months) voluntary exercise. Herein, we evaluated the effect of short-term (1-week) voluntary wheel running. We found that running improved fragility of tibialis anterior muscle (TA), but not plantaris muscle, independently of utrophin up-regulation, without affecting weakness. Moreover, TA muscle excitability was also preserved by running, as shown by compound muscle action potential measurements after lengthening contractions. Of interest, the calcineurin inhibitor cyclosporin A prevented the effect of running on both muscle fragility and excitability. Cyclosporin also prevented the running-induced changes in expression of genes involved in excitability (Scn $4 a$ and Cacna1s) and slower contractile phenotype (Myh2 and Tnni1) in TA muscle. In conclusion, short-term voluntary exercise improves TA muscle fragility in $m d x$ mice, without worsening weakness. Its effect was related to preserved excitability, calcineurin pathway activation, and changes in the program of genes involved in excitability and slower contractile phenotype. Thus, remediation of muscle fragility of Duchenne muscular dystrophy patients through appropriate exercise training deserves to be explored in more detail. (Am J Pathol 2018, 188: 2662-2673; https://doi.org/10.1016/j.ajpath.2018.07.015)
\end{abstract}

Duchenne muscular dystrophy (DMD) is a disorder affecting both skeletal and cardiac muscles, caused by dystrophin deficiency, a subsarcolemmal protein that plays a role in force transmission and sarcolemma stability. ${ }^{1-3}$ Skeletal muscle of the dystrophin-deficient $m d x$ mice, a murine model for DMD, exhibits weakness [ie, reduced specific maximal force (absolute maximal force generated relative to muscle cross-sectional area or weight)]. ${ }^{4-6}$ The $m d x$ skeletal muscle is also more fragile [ie, susceptible to damage caused by lengthening (eccentric) contractions, which cause an immediate marked force decrease after lengthening contractions in fast low oxidative muscle in $m d x$ mice, but not slow oxidative muscle]. ${ }^{7-9}$ Recently, it was found that reduced excitability (ie, plasmalemma electrical dysfunction) largely contributes to the immediate force decrease after lengthening contractions in $m d x$ mouse muscle. ${ }^{10}$ These most important functional dystrophic features, weakness and fragility, are both rescued in $m d x$ mice treated with dystrophin restoration-based therapies. ${ }^{10-14}$ Moreover, we previously demonstrated that dystrophin restoration-based therapies in $m d x$ mice reduce the force decrease after lengthening contractions via improved muscle excitability. ${ }^{10}$

\footnotetext{
Supported by Pierre and Marie Curie University, INSERM, Association Institute of Myology, Paris Descartes University, and French Association against Myopathies.

C.D. and J.H. contributed equally to this work.

Disclosures: None declared.
} 
Of interest, chronic muscular exercise can also improve functional dystrophic features. ${ }^{15,16}$ In particular, long-term voluntary exercise-based studies (3 weeks to 13 months), using wheel running, reported increased specific maximal force in hind limb muscle of $m d x$ mice. ${ }^{5,17-19}$ One study also found that long-term voluntary running decreases the force decrease after lengthening contractions in $m d x$ mouse muscle [ie, improves (reduces) fragility]. ${ }^{20}$ The notion that long-term voluntary running is beneficial for hind limb muscle from $m d x$ mice is also supported by the fact that several weeks of physical inactivity aggravates muscle weakness as well as susceptibility to contraction-induced damage.$^{20}$ However, the following are not yet known: i) whether a shorter period (1 week) of voluntary running is also beneficial for functional dystrophic features, ii) whether the beneficial effect of voluntary running is related to improved muscle excitability, and iii) what the mechanisms are behind the beneficial effect of voluntary running. In the context of a possible therapy by chronic muscular exercise, it is important to know whether beneficial effects can be achieved with a shorter duration. A short duration of chronic muscular exercise should allow a better compliance of the patient to the therapy.

Different signaling pathways are activated by exercise in heathy muscle, leading to beneficial muscle remodeling (ie, cellular and molecular muscle adaptations). ${ }^{21-24}$ Numerous studies support the notion that the muscle remodeling induced by chronic exercise, such as the promotion of slower and more oxidative muscle fibers, is dependent on the activation of the calcineurin pathway in healthy muscle. ${ }^{23-28}$ However, it is not yet known whether the beneficial effect of voluntary running in $m d x$ mice is also related to the activation of the calcineurin pathway. Several studies support this hypothesis by showing that activation of the calcineurin pathway alleviates the dystrophic features in $m d x$ muscle. ${ }^{29-32}$ In particular, the overexpression of active calcineurin in tibialis anterior (TA) muscle of $m d x$ mice reduces the force decrease after lengthening contractions. ${ }^{30}$ This result was associated with increased percentage of muscle fibers expressing the slowest myosin heavy chains (MHCs; MHC-1 and MHC-2a) with higher oxidative capacity and utrophin A protein level, a homolog to dystrophin. ${ }^{30,32}$ The slow and more oxidative muscle fibers, which are less fragile and affected in $m d x$ mice, express more utrophin A than the fast less oxidative muscle fibers, ${ }^{8,33,34}$ and utrophin $\mathrm{A}$ is an effective surrogate for dystrophin in $m d x$ muscles. ${ }^{35-37}$ Recently, it was demonstrated that the calcineurin pathway regulates utrophin A expression in skeletal muscle. ${ }^{33}$

Table 1 Sequences of Primers Used

\begin{tabular}{|c|c|c|}
\hline Gene & Forward primer & Reverse primer \\
\hline \multicolumn{3}{|c|}{ Housekeeping gene } \\
\hline Sdha & 5'-TTACAAAGTGCGGGTCGATG-3' & 5'-GTGTGCTTCCTCCAGTGTTC-3' \\
\hline \multicolumn{3}{|c|}{ Genes of interest } \\
\hline Atp1a2 & $5^{\prime}$-GAAGGAGGTTGCCATGGATGA-3' & 5'-AGAATGTCCTGAGCTCGCTG-3' \\
\hline Cacna1 & $5^{\prime}-\mathrm{CCTCATCAGCAAGAAGCAGG-3^{ \prime }}$ & $5^{\prime}-\mathrm{TATGACAGACAGACCCTGGC}-3^{\prime}$ \\
\hline Col1a1 & $5^{\prime}$-ATTCCCGTTCGAGTACGGAA-3' & 5'-CTCGATCTCGTTGGATCCCT-3' \\
\hline Il1B & $5^{\prime}-$ AAGGAGAACCAAGCAACGAC - $3^{\prime}$ & $5^{\prime}$-CTTGGGATCCACACTCTCCAG-3' \\
\hline Myog & $5^{\prime}$-GAGCTATCCGGTTCCAAAGC-3' & $5^{\prime}-\mathrm{TTCCCGGTATCATCAGCACA-3^{ \prime }}$ \\
\hline Myh2 & $5^{\prime}-$ AAGCGAAGAGTAAGGCTGTC-3' & $5^{\prime}$-GTGATTGCTTGCAAAGGAAC-3' \\
\hline Myh3 & 5'-TGAGCAAGACCTCCTGGTG-3' & $5^{\prime}-$ TGCATGTGGAAAAGTGATACG-3' \\
\hline Nduf5 & 5'-TTTCCGAAGACTGTCGCTCC-3' & 5'-TGGGATTTCTGCAAGCTCGG-3' \\
\hline Nrf1 & 5'-GCTGCAGGTCCTGTGGGAATGG-3' & 5'-GCTGTCTCTTTCGGATAGATGG-3' \\
\hline $\operatorname{Pgc1} \alpha$ & $5^{\prime}-\mathrm{GCTCAAGCCAAACCAACA-3^{ \prime }}$ & $5^{\prime}$-CAGTTCCAGAGAGTTCCACA-3' \\
\hline $\operatorname{Pgc1} \beta$ & $5^{\prime}$-GGAGACTGCTCTGGAAGGTG-3' & $5^{\prime}$-GGAAGCTACTCTCGCCACTG-3' \\
\hline Rcan1 & $5^{\prime}-$ ATGGAGGAGGTGGATCTGC-3' & 5'-TTCAAATTTGGCCCGGCAC-3' \\
\hline Rcan3 & $5^{\prime}$-GACCTAAGTGACCTGCCCAC-3' & 5'-TCGGGCTTGCTGAAGTTGAT-3' \\
\hline $\operatorname{Scn} 4 a$ & 5'-GCAACCTGGTGGTCCTGAAT-3' & $5^{\prime}-$ CAGCCCCAAGAGGAAGGTTT-3' \\
\hline$S d h b$ & 5'-TGCCATTTACCGATGGGACC-3' & $5^{\prime}$-CAAGAGCCACAGATGCCTTC- $3^{\prime}$ \\
\hline Tfam & 5'-тCСССTCGTCTATCAGTCTTGT-3' & $5^{\prime}$-CCACAGGGCTGCAATTTTCC-3' \\
\hline TGF1 & 5'-CTGCTTTAGAAATGTGCAGG-3' & $5^{\prime}$-CAGAAGTTAGCATTGTACCC-3' \\
\hline TNF & 5'-TCTCATGCACCATCAAGGACT-3' & $5^{\prime}$-АССАСТСТСССТTTGCAGAACTCA-3' \\
\hline
\end{tabular}


Our aim was to analyze the effect of short-term voluntary running, initiated at the age of 2 to 4 months, on hind limb muscle weakness and fragility of $m d x$ mice. One week of voluntary running (wheel) improved susceptibility to damage caused by lengthening contractions in $m d x$ mice. This improvement of muscle fragility was related to changes in muscle excitability. Finally, the calcineurin inhibitor, cyclosporin A (CsA), blocked the effect of voluntary running and prevented the changes in the expression of calcineurinrelated genes, supporting the hypothesis that activation of the calcineurin pathway plays a role in the beneficial effect of short-term voluntary exercise in $m d x$ mice.

\section{Materials and Methods}

\section{Animals and Voluntary Running}

All procedures were performed in accordance with national and European legislations and were approved by our institutional Ethics Committee Charles Darwin (project 01362.02). The $m d x$ mice (C57BL/10ScSc-DMDMdx/J; $\mathrm{Mdx})$ and sex- and age-matched wild-type control mice (C57BL/10; C57) were used. Mice were randomly divided into different control and experimental groups. Mice at 2 to 4 months of age were placed in separate cages containing a wheel and were allowed to run 1 week ad libitum (Mdx + wheel). The running distances were collected. In addition, a group of $m d x$ mice were exercised every day during 1 week on a horizontal motorized treadmill ( 5 minutes at $5 \mathrm{~cm} / \mathrm{second}, 5$ minutes at $10 \mathrm{~cm} / \mathrm{second}$, 5 minutes at $15 \mathrm{~cm} / \mathrm{second}$, and 45 minutes at 15 to $18 \mathrm{~cm} /$ second). In some experiments, mice were treated every day during 1 week with the calcineurin pathway inhibitor cyclosporine A ( $25 \mathrm{mg} / \mathrm{kg}$, intraperitoneally, daily).

\section{Muscle Weakness and Fragility}

Muscle weakness (reduced specific maximal force) and fragility (susceptibility to contraction-induced injury) were evaluated by measuring the in situ TA muscle contraction in response to nerve stimulation, as described previously. $^{10,20,38}$ In some experiments, extensor digitorum longus (EDL), gastrocnemius, and plantaris muscles were also studied. Mice were anesthetized using pentobarbital (60 mg/kg, intraperitoneally). Body temperature was maintained at $37^{\circ} \mathrm{C}$ using radiant heat. The knee and foot were fixed with pins and clamps, and the distal tendon of the muscle was attached to a lever arm of a servomotor system (305B, Dual-Mode Lever; Aurora Scientific, Aurora, ON, Canada) using a silk ligature. The sciatic nerve was proximally crushed and distally stimulated by a bipolar silver electrode using supramaximal square wave pulses of 0.1 -millisecond duration. The absolute maximal force that was generated during isometric contractions in response to electrical stimulation (frequency of 75 to $150 \mathrm{~Hz}$, train of stimulation of 500 milliseconds) was measured. Absolute maximal force was determined at L0 (length at which maximal tension was obtained during the tetanus). Absolute maximal force was normalized to the muscle mass as an estimate of specific maximal force, an index of muscle weakness.

Fragility (ie, susceptibility to contraction-induced injury in $\mathrm{mdx}$ mice) was estimated from the force decrease resulting from lengthening contraction-induced injury. The sciatic nerve was stimulated for 700 milliseconds (frequency of $150 \mathrm{~Hz}$ ). A maximal isometric contraction of the TA muscle was initiated during the first 500 milliseconds. Then, muscle lengthening (10\% L0) at a velocity of $5.5 \mathrm{~mm} /$ second ( 0.85 fiber length/second) was imposed during the last 200 milliseconds. All isometric contractions were made at an initial length L0. Nine lengthening contractions of the TA muscles were performed in mdx mice, each separated by a 60-second rest period. Because the susceptibility to contraction-induced injury is lower in C57 mice, ${ }^{7,8}$ in an experiment, C57 mice performed 18 lengthening contractions. The first nine lengthening contractions were similar as for mdx mice, but the muscle lengthening was greater $(20 \%$ L0) during the nine last lengthening contractions. Maximal isometric force was measured 1 minute after each lengthening contraction and expressed as a percentage of the initial maximal force. After contractile measurements, the animals were sacrificed with cervical dislocation.

\section{Electromyography}

For compound muscle action potential (CMAP) recordings, two monopolar needle electrodes were inserted into the belly of the TA muscle. ${ }^{10}$ The recording (cathode) and the reference (anode) electrodes were inserted into the proximal and the distal portion of the muscle, respectively. A third monopolar electrode was inserted in the contralateral hind limb muscle to ground the system. Data were amplified (BioAmp; ADInstruments, Sydney, NSW, Australia), acquired with a sampling rate of $100 \mathrm{kHz}$, and filtered at 5 kHz low pass and $1 \mathrm{~Hz}$ high pass (Powerlab 4/25; ADInstruments). Recording electrodes were positioned to achieve maximal CMAP amplitude. CMAPs were recorded during lengthening contractions, and the root mean square of the CMAP was calculated, as an index of CMAP amplitude. The root mean square of each CMAP corresponding to each contraction was then expressed as a percentage of the first contraction, used as a marker of muscle excitability.

\section{Real-Time Quantitative PCR}

Muscles (TA and plantaris) were snap frozen in liquid nitrogen and stored at $-80^{\circ} \mathrm{C}$ until use. Total RNA was isolated from TA and plantaris muscle tissues using Trizol (Invitrogen, Carlsbad, CA). cDNA was then synthesized from $1 \mu \mathrm{g}$ of total RNA using the RevertAid First Strand cDNA Synthesis kit with random hexamers, according to the manufacturer's instructions (Thermo Fisher Scientific, Waltham, 
MA). RT-PCR was performed on a LightCycler 480 System at the platform iGenSeq of the Brain and Spinal Cord Institute, using LightCycler 480 SYBR Green I Master Mix (Roche, Basel, Switzerland). ${ }^{39}$ The expressions of succinate dehydrogenase complex flavoprotein subunit A and hydroxymethylbilane synthase were used as reference transcripts. All sequences of primers used are presented in Table 1.

\section{Western Blot Analysis}

TA muscle tissue samples were disrupted in a homogenizer (Psychotron NS-310EII; Microtec Co, Ltd, Chiba, Japan) in $100 \mu \mathrm{L}$ of lysis buffer $(7 \mathrm{~mol} / \mathrm{L}$ urea, $2 \mathrm{~mol} / \mathrm{L}$ thiourea, $2 \%$ CHAPS, and $50 \mathrm{mmol} / \mathrm{L}$ dithiothreitol). Samples were centrifuged at $20,000 \times g$ for 30 minutes, and the supernatant was stored at $-20^{\circ} \mathrm{C}$. Protein concentrations were determined by the Bio-Rad protein assay (Bio-Rad Life Science, Hercules, CA), with bovine serum albumin as the standard. Muscle proteins were separated by SDS-PAGE (4\% to $20 \%$ polyacrylamide) and electroblotted onto a nitrocellulose membrane. Membranes were stained with Ponceau S solution (0.1\% Ponceau $\mathrm{S}$ in $1 \%$ acetic acid) to ensure equal loading and efficient transfer of the protein samples. After blocking with $1 \%$ bovine serum albumin, membranes were incubated overnight with antibody against utrophin A NCL-DRP2 (Novocastra, Concord, ON, Canada). After the incubation period, primary antibodies were washed $3 \times$ for 5 minutes in tris-buffered saline and Tween 20 . The appropriate dilution of secondary antibody coupled to horseradish peroxidase was applied to the membrane in blocking solution for 1 hour at room temperature. The membrane was washed $3 \times$ for 5 minutes in tris-buffered saline and Tween 20 and visualized with enhanced chemiluminescence (Western Lighting ECL; PerkinElmer, Woodbridge, ON, Canada). Membranes were developed with the Super Signal West Femto Chemiluminescent Kit (Thermo Fisher Scientific). Images were captured and analyzed using ImageJ software version $1.45 \mathrm{~s}$ (NIH, Bethesda, MD; http://imagej.nih.gov/ij).

\section{Statistical Analysis}

Groups were statistically compared using $t$-test and variance analysis (one or two ways). If necessary, a subsequent Bonferroni post hoc test was also performed. For groups that did not pass tests of normality and equal variance, nonparametric tests were used (Kruskal-Wallis and Wilcoxon). Values are means \pm SEM.

\section{Results}

Voluntary Running Improves Both Muscle Fragility and Excitability in Anterior Crural Muscles from $m d x$ Mice

Isometric muscle force production in response to tetanic nerve stimulation $(125 \mathrm{~Hz}, 500$ milliseconds) was analyzed in TA muscle of $m d x$ and healthy C57 mice. An immediate force decrease was observed after the third, sixth, and ninth lengthening contractions in $m d x$ mice $(P<0.05)$ (Figure 1A). There was no such force decrease after nine lengthening contractions in C57 mice (Figure 1A). This measure evidenced the higher susceptibility to contractioninduced injury in $m d x$ mice (ie, fragility). When $m d x$ mice were subjected to 1 week of voluntary training $(\mathrm{Mdx}+$ wheel; daily distance traveled $=4.5 \pm 0.4 \mathrm{~km})$, the force decrease after lengthening contractions was reduced compared with $m d \mathrm{x}$ mice $(P<0.05)$ (Figure $1 \mathrm{~A})$. Moreover, voluntary running did not affect specific maximal force before lengthening contractions (Figure 1B). Therefore, 1-week voluntary running in $m d x$ mice decreased TA muscle fragility, without worsening weakness (Figure 1B).

The force decrease after lengthening contractions is explained by decreased muscle excitability. ${ }^{10}$ In parallel to the isometric TA muscle force production, electromyography was used to measure the CMAP in response to nerve stimulation, a marker of muscle excitability. CMAP (root mean square) decreased after lengthening contractions in $m d x$ mice $(P<0.05)$, similarly to maximal force (Figure 1A). Of interest, CMAP was less decreased by lengthening contractions in $\mathrm{Mdx}+$ wheel mice compared with $m d x$ mice $(P<0.05)$ (Figure $1 \mathrm{~A})$, indicating that both improvements in TA muscle fragility and excitability of Mdx + wheel were related.
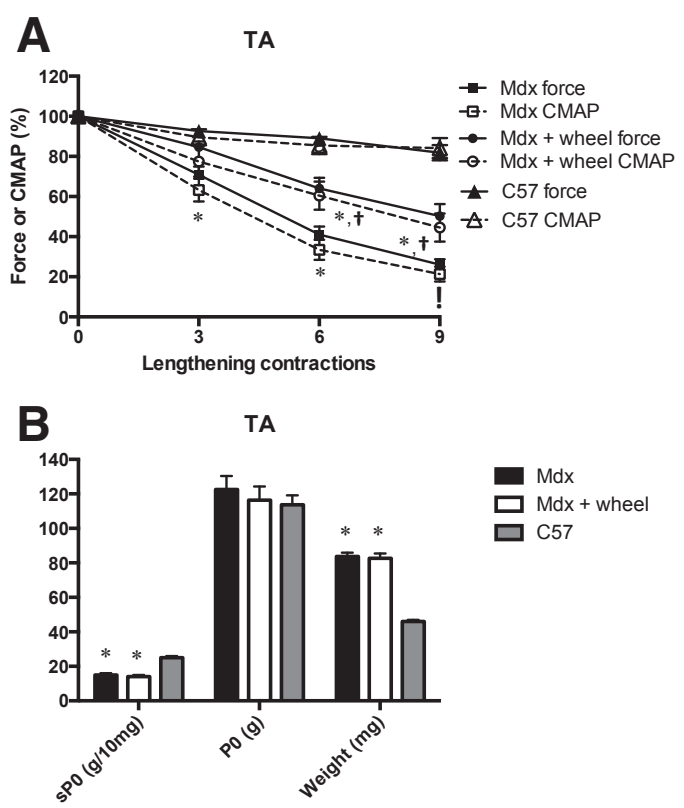

Figure 1 Fragility, excitability, and weakness in tibialis anterior (TA) muscle from 1-week voluntary wheel runner $m d x$ mice (Mdx + wheel). A: Force and compound muscle action potential (CMAP; root mean square) after lengthening contractions. B: Specific ( $\mathrm{SP}$ ) and absolute ( $\mathrm{PO}$ ) maximal force and muscle weight before lengthening contractions. Data are expressed as means \pm SEM. $n=12$ to 16 per group. ${ }^{*} P<0.05$, significantly different from healthy mice (C57); ${ }^{\dagger} P<0.05$ versus $\mathrm{Mdx}$. 
Similarly, the same beneficial effect of voluntary running on EDL muscle, another crural muscle, was reported from $m d x$ mice, because the decrease force after lengthening contractions was lower in $\mathrm{Mdx}+$ wheel compared with $m d x$ $(P<0.05)$ (Figure 2A), without a difference in maximal force (Figure $2 \mathrm{~B}$ ). Therefore, short-term voluntary running has a beneficial effect on fragility of both anterior crural muscles (TA and EDL; ie, dorsiflexor ankle muscles in $m d x$ mice).

In contrast with voluntary running, 1 week of forced treadmill running (daily distance traveled $=0.5 \mathrm{~km}$ ) had no effect on either the force decrease after lengthening contractions, the decrease in CMAP, or the specific maximal force in TA muscle from $m d x$ mice (Figure 2, C and D). Muscle weight was reduced in $\mathrm{Mdx}+$ treadmill compared with $m d x(P<0.05)$ (Figure $2 \mathrm{D})$; however, absolute maximal force was not significantly reduced $(P=0.06)$. Together, these results indicated that the beneficial effect of exercise on TA muscle depends on the type of running (wheel/voluntary versus treadmill/forced running) in $m d x$ mice.

Next, it was determined whether voluntary running (daily distance traveled $=9.8 \pm 2.0 \mathrm{~km}$ ) also improves fragility in C57 mice. Eighteen lengthening contractions, a more severe lengthening contraction protocol than the protocol used for $m d x$ mice (only nine lengthening contractions), were used to induce a marked force decrease in TA muscle from C57 mice $(P<0.05)$ (Figure $2 \mathrm{E})$. Electromyography analysis indicated that CMAP was also severely decreased after 18 lengthening contractions in C57 mice $(P<0.05)$
(Figure 2E). However, no difference between C57 + wheel mice and C57 mice was observed concerning the force decrease and the CMAP decrease after lengthening contractions and specific maximal force (Figure 2, E and F), indicating that the beneficial effect of voluntary running on TA muscle was specific to $\mathrm{Mdx}+$ wheel mice but not C57 + wheel mice.

\section{CsA Prevents the Benefits of Voluntary Running on Fragility and Excitability in TA Muscle from $m d x$ Mice}

To determine whether the reduced TA muscle force decrease after lengthening contractions induced by voluntary running was related to calcineurin signaling, $\mathrm{Mdx}+$ wheel mice were treated with the calcineurin inhibitor, CsA (Mdx + wheel + CsA mice). The muscle force decrease after lengthening contractions was greater $(P<0.05)$ in $\mathrm{Mdx}+$ wheel + CsA mice (daily distance traveled $=4.7 \pm 0.5$ ) compared with $\mathrm{Mdx}+$ wheel mice (daily distance traveled $=5.6 \pm 1.4 \mathrm{~km}$ ) (Figure 3A), indicating that CsA prevented the improvement in fragility induced by voluntary running, without affecting specific maximal force (Figure 3B). Therefore, these results suggest that the improvement of fragility in TA muscle from $\mathrm{Mdx}+$ wheel is related to calcineurin pathway activation.

Next, the changes in both force and CMAP were simultaneously measured after lengthening contractions in TA muscle from $\mathrm{Mdx}+$ wheel + CsA mice. Both the force decrease (Figure 3C) and CMAP decrease (Figure 3D) were not different in Mdx + wheel + CsA mice (daily distance
A
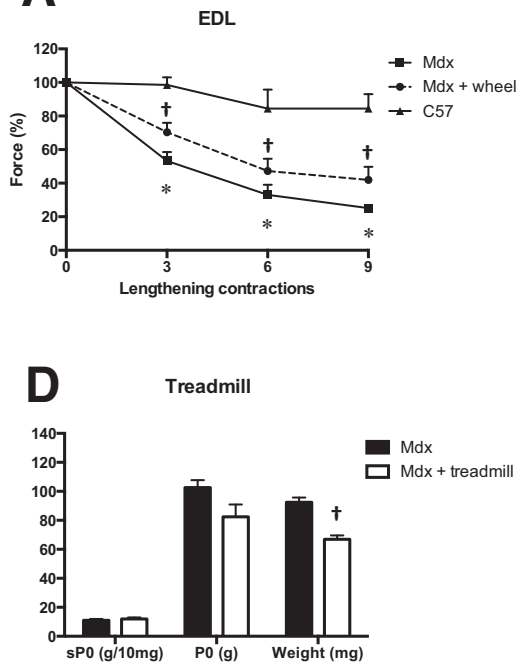

B

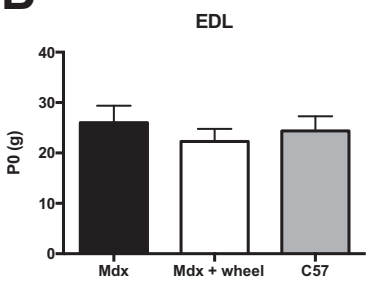

E

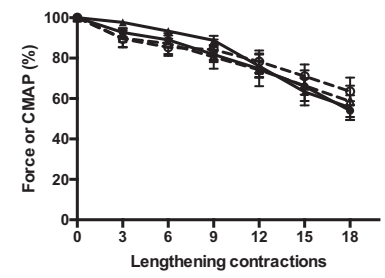

C

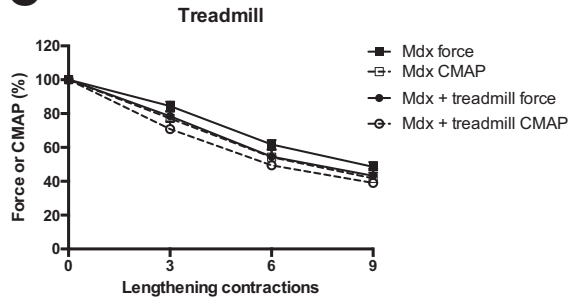

$\mathbf{F}$

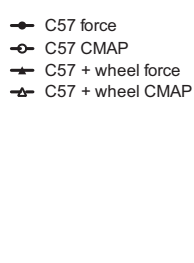

C57

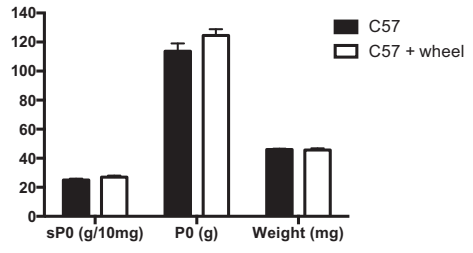

Figure 2 Fragility and weakness in extensor digitorum longus (EDL) muscle from 1-week voluntary wheel runner $m d x$ mice (Mdx + wheel), in tibialis anterior (TA) muscle from 1-week forced treadmill runner $m d x$ mice ( $M d x+$ treadmill) and in TA muscle from 1-week voluntary wheel runner healthy mice (C57). A: Force after lengthening contractions in EDL muscle from Mdx + wheel. B: Absolute (P0) maximal force before lengthening contractions in EDL muscle from Mdx + wheel. C: Force and compound muscle action potential (CMAP; root mean square) after lengthening contractions in TA muscle from Mdx + treadmill. D: Specific (sP0) and PO maximal force and muscle weight before lengthening contractions in TA muscle from Mdx + treadmill. E: Force and CMAP (root mean square) after lengthening contractions in TA muscle from 1-week voluntary wheel runner C57. F: sP0 and P0 maximal force and muscle weight before lengthening contractions in TA muscle from 1-week voluntary wheel runner C57. Data are expressed as means \pm SEM. $n=8$ to 10 per group (A); $n=12$ to 14 per group (C); $n=10$ to 16 per group (E). ${ }^{*} P<0.05$ versus $C 57 ;{ }^{\dagger} P<0.05$ versus $\mathrm{Mdx}$. 

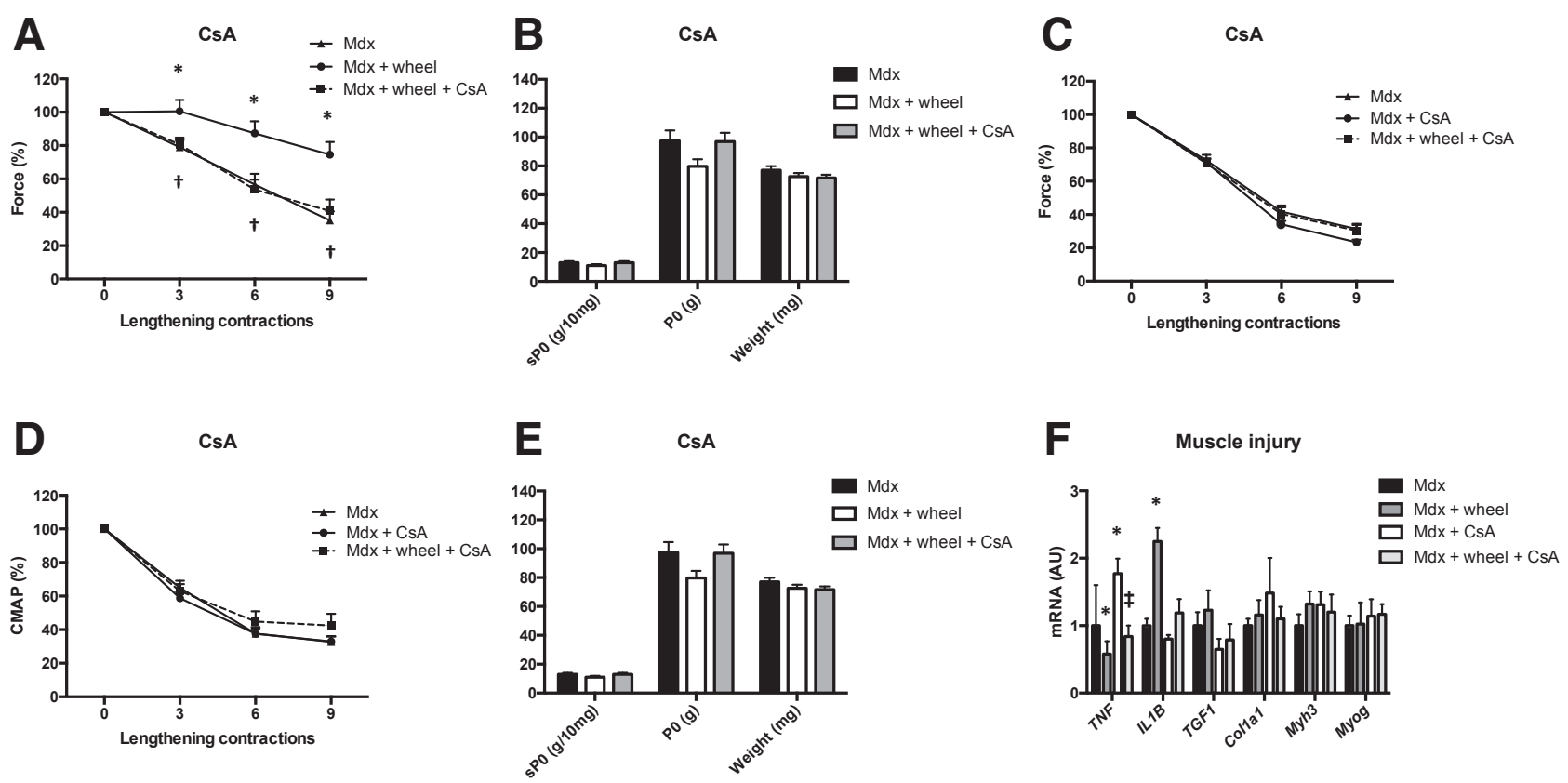

Figure 3 Fragility and weakness in tibialis anterior muscle from 1-week voluntary wheel runner $m d x$ mice that were treated with cyclosporine A (CsA; Mdx + wheel + CsA). A: Force after lengthening contractions in $\mathrm{Mdx}+$ wheel + CsA mice compared with Mdx + wheel mice. B: Specific (sPO) and absolute ( $\mathrm{PO}$ ) maximal force and muscle weight before lengthening contractions. C: Force after lengthening contractions in $\mathrm{Mdx}+$ wheel $+\mathrm{CsA}$ compared with Mdx + CsA. D: Compound muscle action potential (CMAP; root mean square) after lengthening contractions. E: SP0 and P0 maximal force and muscle weight before lengthening contractions. F: Expression of genes, markers of muscle injury (inflammation, fibrosis, and myogenesis). Data are expressed as means \pm SEM. $n=10$ to 12 per group (A); $n=12$ to 26 per group (C); $n=6$ to 16 per group (F). ${ }^{*} P<0.05$ versus $M d x ;{ }^{\dagger} P<0.05$ versus $\mathrm{Mdx}+$ wheel; ${ }^{\ddagger} P<0.05$ versus $\mathrm{Mdx}+$ CSA. AU, arbitrary unit.

traveled $=4.1 \pm 1.6 \mathrm{~km}$ ) compared with $\mathrm{Mdx}+\mathrm{CsA}$, confirming that changes in force and CMAP after lengthening contractions are related. Of interest, CsA had no effect on either fragility or maximal force and muscle weight in $\mathrm{Mdx}+$ CsA mice compared with $m d x$ mice (Figure 3, C and E). These results demonstrate that the effect of CsA during voluntary running on TA muscle fragility was attributable to prevention of changes in both force and CMAP and not to an inherent damaging effect on $m d x$ muscles.

Altogether, these results indicate that the improvement of TA muscle fragility and excitability provided by voluntary running is related to calcineurin pathway activation, because its inhibition by CsA prevents these beneficial effects. Moreover, voluntary running induced no detrimental effect because the markers of muscular damage were not aggravated. The expressions of TNF, TGFB1, Collal, Myh3, and Myog (markers of inflammation, fibrosis, and myogenesis) were not increased in TA muscle from $\mathrm{Mdx}+$ wheel mice compared with $m d x$ mice, except $I L 1 B$, as assessed by real-time quantitative PCR analysis (Figure 3F).

\section{Voluntary Running Activates the Calcineurin Pathway in TA Muscle from $m d x$ Mice}

It is well accepted that exercise activates the calcineurin pathway. ${ }^{23-25,27,28}$ To evaluate the regulation of the calcineurin pathway induced by voluntary exercise, it was determined whether voluntary running modulates the expression of key genes regulating the calcineurin pathway in TA muscle from $\mathrm{Mdx}+$ wheel mice. The expression of calcineurin regulator genes Rcan3, Cmya5, and Myoz $1^{40,41}$ changed by voluntary running $(P<0.05)$, but not Rcanl, irrespective of CsA treatment (Figure 4A). As further proof that the calcineurin pathway was activated in TA muscle from $\mathrm{Mdx}+$ wheel mice, CsA prevented the changes in slow contractile gene expression induced by voluntary running, genes whose expression is known to be related to calcineurin pathway activation (see below). Together, these results support the notion that the calcineurin pathway is activated in TA muscle of $m d x$ mice by voluntary running.

\section{CsA Prevents the Changes Induced by Voluntary Running in the Expression of Several Genes Involved in Excitability in TA Muscle of $m d x$ Mice}

Our results indicate that TA muscle excitability after lengthening contractions was improved by voluntary exercise in $\mathrm{Mdx}+$ wheel mice. Several genes coding membrane channels are involved in muscle excitability, such as $\operatorname{Scn} 4 a$, Cacnals, Clcn1, Slc8a1, and Atpla2. ${ }^{42}$ Thus, it was tested whether voluntary running modulates the expression of these channels in TA muscle. In agreement, it was found that the expression of Snc4a, Cacnals, and Slc8al was changed by voluntary exercise in $\mathrm{Mdx}+$ wheel mice 

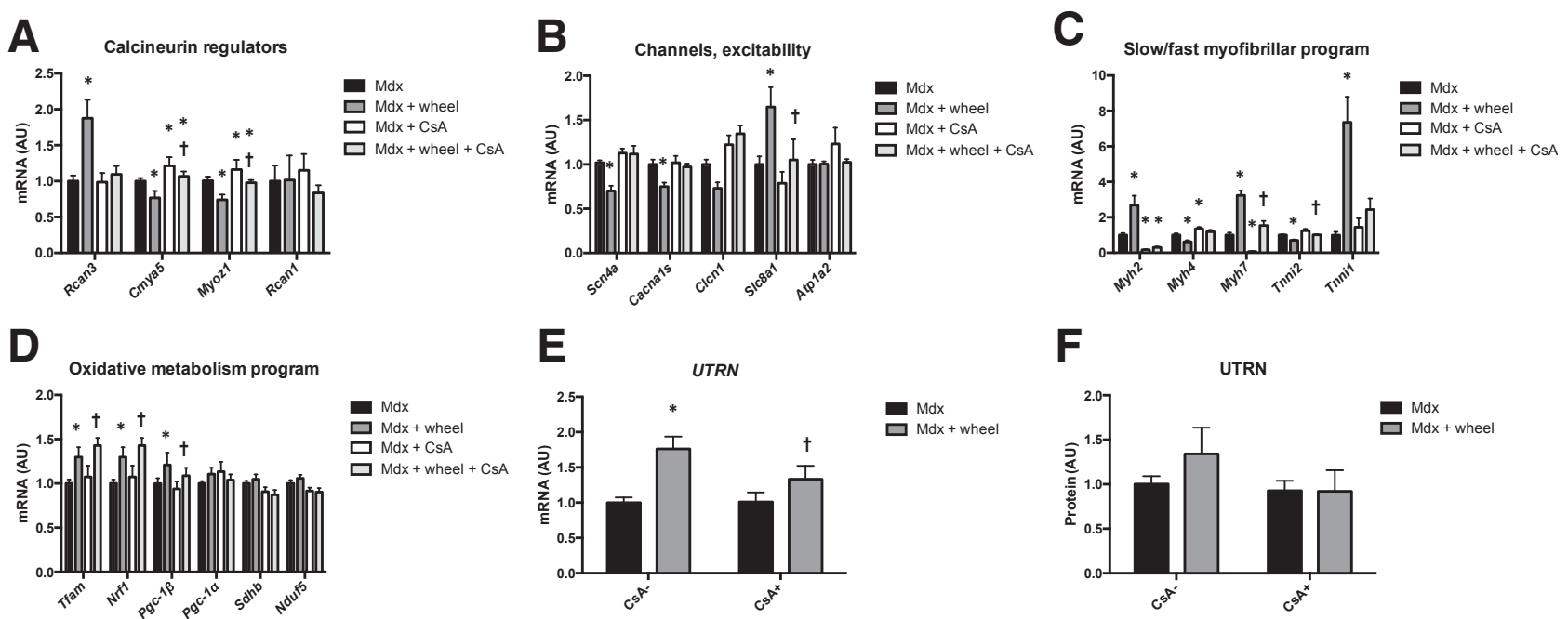

Figure 4 Expression of genes regulating the calcineurin pathway, involved in excitability, the slow/fast myofibrillar program, the oxidative metabolism program, and utrophin protein in tibialis anterior muscle from 1-week voluntary wheel runner $m d x$ mice treated with cyclosporine $\mathrm{A}(\mathrm{Cs} \mathrm{A}$; Mdx + wheel $+\operatorname{Cs} \mathrm{A})$ or left untreated. A: Genes regulating the calcineurin pathway. B: Genes involved in excitability. C: Genes involved in the slow/fast myofibrillar program. D: Genes involved in the oxidative metabolism program. E: Utrophin gene. F: Utrophin (UTRN) protein. Data are expressed as means \pm SEM. $n=7$ to 17 per group (A-E); $n=5$ to 10 per group (F). ${ }^{*} P<0.05$ versus $M d x ;{ }^{\dagger} P<0.05$ versus $M d x+C s A$. AU, arbitrary unit.

compared with $m d x$ mice $(P<0.05)$ (Figure 4B), but not Clcnl and Atpla2 (Figure 4B). Furthermore, CsA prevented the down-regulation of $\operatorname{Scn} 4 a$ and Cacnals induced by voluntary running because no difference was found between $\mathrm{Mdx}+$ wheel + CsA mice and Mdx + CsA mice (Figure 4B). Together, these results suggested that the improved TA muscle excitability and fragility after lengthening contractions induced by voluntary running and the activation of the calcineurin pathway were related to $\operatorname{Scn} 4 a$ and Cacnals down-regulation.

\section{CsA Prevents the Up-Regulation of Slow Contractile} Genes Induced by Voluntary Running in TA Muscle from $m d x$ Mice

The calcineurin pathway is a key regulator of slow contractile muscle fiber program. ${ }^{25,43}$ In agreement, it was found that the expression of most of the studied contractile genes (Myh2, Myh4, Myh7, and Tnni2) was changed by CsA in TA muscle from Mdx + CsA mice compared with $m d x$ mice $(P<0.05)$ (Figure $4 \mathrm{C})$.

Exercise also plays an important role in the promotion of the slower contractile phenotype. ${ }^{23,24,27}$ In line, voluntary running up-regulated slow (or the slowest) contractile genes $(M y h 2, M y h 7$, and Tnnil) $(P<0.05)$ (Figure 4C) and downregulated fast contractile genes (Myh4 and Tnni2) $(P<0.05)$ (Figure $4 \mathrm{C})$ in TA muscle from $\mathrm{Mdx}+$ wheel mice compared with $m d x$ mice, indicating that a fast-to-slow contractile gene program transition occurs in the absence of CsA. Of interest, it was found that CsA prevents the upregulation of Myh2 and Tnnil (Figure 4C) induced by voluntary running because no difference was found between $\mathrm{Mdx}+$ wheel + CsA mice and Mdx + CsA mice. Together, these results suggest that the improved TA muscle fragility induced by voluntary running is related to Myh2 and Tnnil up-regulation because of calcineurin pathway activation.

\section{CsA Does Not Prevent the Up-Regulation Induced by Voluntary Running of the 0xidative Gene Program in TA Muscle from $m d x$ Mice}

Exercise is also a key regulator of oxidative muscle fiber phenotype. $^{21,24}$ In agreement, it was found that voluntary running up-regulated the expression of Tfam, Nrfl, and $P g c 1-\beta$ in TA muscle from $\mathrm{Mdx}+$ wheel mice compared with $m d x$ mice $(P<0.05)$ (Figure $4 \mathrm{D})$, but not $P g c-1 \alpha$, $S d h b$, and Nduf5 (Figure 4D). Furthermore, CsA did not prevent the up-regulation of these genes (Tfam, Nrfl, and $P g c 1-\beta$ ) (Figure 4D) induced by voluntary running, suggesting that the improved TA muscle fragility is not related to oxidative metabolism up-regulation.

\section{Voluntary Running Does Not Increase the Utrophin Protein Level in TA Muscle from $m d x$ Mice}

Because genetic interventions that induce high levels of utrophin A, a homolog of dystrophin, improve the force decrease after lengthening contractions in $m d x$ mice, ${ }^{36,37}$ it was determined whether voluntary running increases utrophin A expression in TA muscle. The increased expression of the transcript coding for utrophin induced by voluntary running was not blocked by CsA (Figure 4E). Moreover, the protein level of utrophin A was not increased in $\mathrm{Mdx}+$ wheel mice compared with $m d x$ mice (Figure 4F). Thus, the improved TA muscle fragility was not related to increased utrophin A protein levels. 
Voluntary Running Does Not Improve Muscle Fragility and Excitability in Posterior Crural Muscles from $m d x$ Mice

To determine whether the beneficial effect of voluntary running is dependent of the muscle group (anterior versus posterior crural muscles), posterior crural muscles (ie, plantaris and gastrocnemius muscles) were analyzed. The force decrease of both plantaris and gastrocnemius muscles after lengthening contractions was not changed in $\mathrm{Mdx}+$ wheel mice compared with $m d x$ mice $(P<0.05)$ (Figure 5, A and B). Moreover, voluntary running did not affect specific maximal force of both plantaris and gastrocnemius muscles before lengthening contractions (Figure 5, C and D). Therefore, in contrast to TA and EDL muscles, 1-week voluntary running in $m d x$ mice did not change plantaris and gastrocnemius muscle fragility, indicating that the beneficial effect of voluntary running on fragility is muscle group dependent.

\section{Voluntary Running Does Not Modulate the Expression of the Selected Genes in Plantaris from $m d x$ Mice}

In contrast to TA muscle, no change was found in the expression of Rcan3, Cmya5, and Myozl (Figure 6A), no down-regulation was found of the expression of $\operatorname{Scn} 4 a$ and Cacnals (Figure 6B), and no increase was found in the expression of Myh2 and Tnnil (Figure 6C) in plantaris muscle from $\mathrm{Mdx}+$ wheel mice. Moreover, similarly to TA muscle, the expression of Pgcl- $\beta$ was increased in plantaris muscle from $\mathrm{Mdx}+$ wheel mice (Figure 6D). Thus, these results regarding TA and plantaris muscles support the notion that the beneficial effect of voluntary exercise is related to calcineurin activation and the change in the expression of Scn4a, Cacnals, Myh2, and Tnnil but not Pgcl- $\beta$.

\section{Discussion}

Improved Muscle Fragility Is Limited to Anterior Crural Muscles, Voluntary Running, and $m d x$ Mice

Our study demonstrates that short-term voluntary running, initiated at 2 to 4 months of age, alleviates the fragility caused by lengthening contractions in fast anterior crural muscles (TA and EDL) of $m d x$ mice, without affecting weakness (specific maximal force). In line, a previous study has shown that long-term voluntary running, initiated at 4 weeks of age, improves this dystrophic feature in $m d x$ mice. ${ }^{20}$ In contrast, long-term voluntary running does not improve susceptibility to contraction-induced injury when it is initiated at 7 months of age in $m d x$ mice. ${ }^{44} \mathrm{An}$ explanation of this discrepancy could be differences in stage of the dystrophic process (more or less intense muscle remodeling). The improvement in fragility by short-term voluntary running was specific to $m d x$ mice (not observed
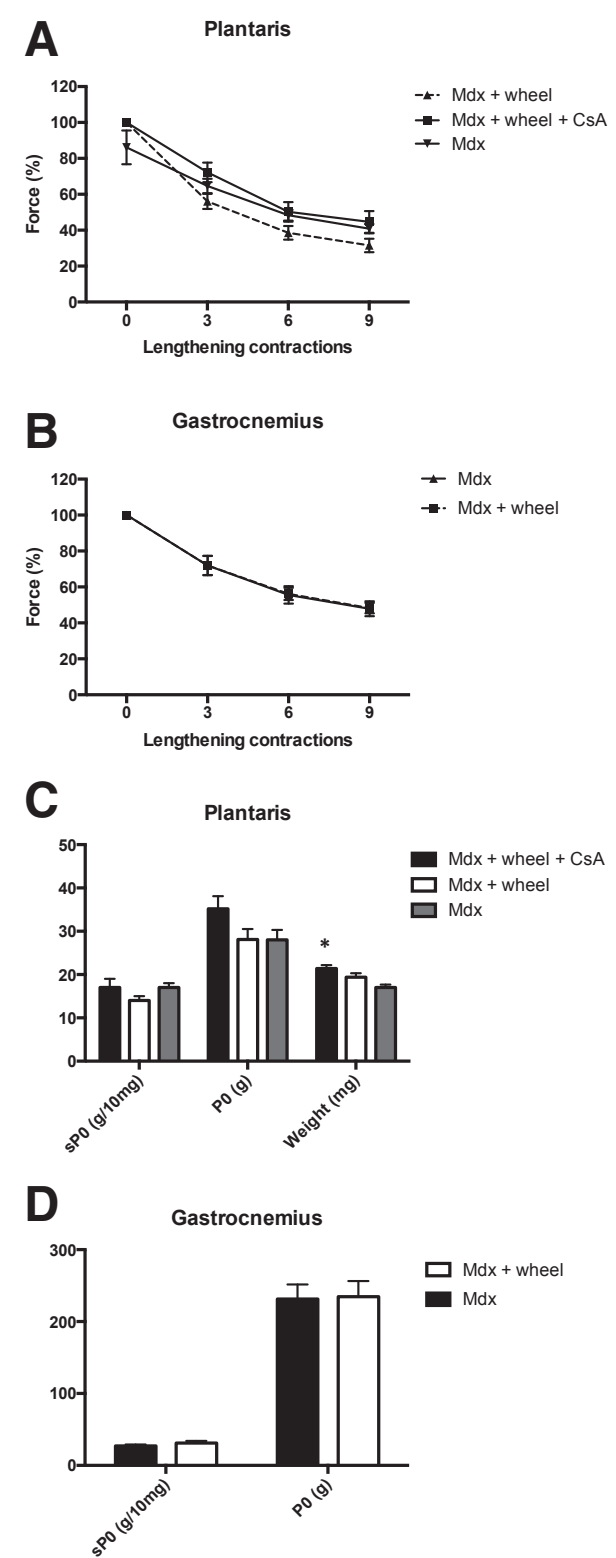

Figure 5 Fragility and weakness in plantaris and gastrocnemius muscles from 1-week voluntary wheel runner $m d x$ mice (Mdx + wheel). A: Force after lengthening contractions in plantaris muscle. B: Force after lengthening contractions in gastrocnemius muscle. C: Specific (sP0) and absolute (PO) maximal force in plantaris muscle and muscle weight before lengthening contractions. D: SP0 and P0 maximal force in gastrocnemius muscle, before lengthening contractions. Data are expressed as means \pm SEM. $n=14$ to 18 per group (A); $n=10$ to 12 per group (B). ${ }^{*} P<0.05$ versus $M d x$. CsA, cyclosporine $A$.

in C57 mice) and to voluntary running (not observed after forced treadmill running). It is expected that $m d x$ mice performed voluntary wheel running that is not harmful, adapting the amount/intensity of activity to their own capacities. In contrast, forced treadmill running can be detrimental because some studies have reported that longterm treadmill running reduced specific maximal force in EDL muscle from $m d x$ mice (ie, aggravated muscle weakness). ${ }^{45,46}$ Together, these studies indicate that voluntary 

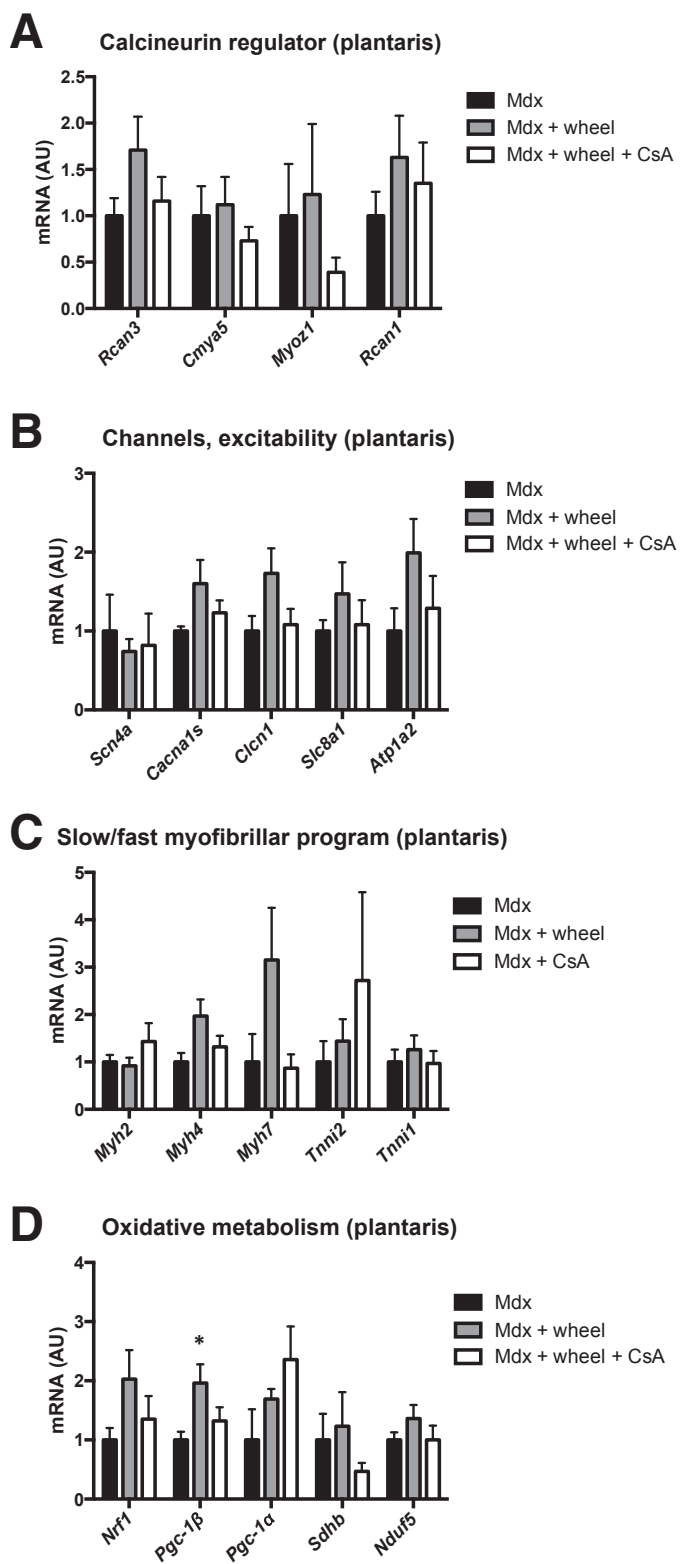

Figure 6 Expression of genes regulating the calcineurin pathway, involved in excitability, the slow/fast myofibrillar program, the oxidative metabolism program, and utrophin protein in plantaris muscle from 1-week voluntary wheel runner $m d x$ mice treated with cyclosporine A (CsA; Mdx + wheel $+(\mathrm{Cs})$ or left untreated. A: Genes regulating the calcineurin pathway. B-D: Genes involved in excitability (B), the slow/fast myofibrillar program (C), and the oxidative metabolism program (D). Data are expressed as means \pm SEM. $n=6$ to 10 per group. ${ }^{*} P<0.05$ versus Mdx.

running improves fragility of the anterior crural muscles (TA and EDL, dorsiflexor ankle muscles), in the younger adult $m d x$ mice, whatever the duration of running, but not posterior crural muscles (plantaris and gastrocnemius, dorsal extensor ankle muscles). This improvement in fragility by voluntary running could be beneficial if it is assumed that fragility causes the exhaustion of the muscle stem cells during successive degeneration/repair cycles. ${ }^{47}$

\section{Improved Fragility Is Explained by Preserved} Excitability

The marked force decrease after lengthening contractions observed in $m d x$ mice can be related to changes in the cascade of events responsible for muscle excitationcontraction-relaxation processes. Lengthening contractions in $m d x$ mice can damage neuromuscular transmission, excitability, calcium release, and uptake in the sarcoplasmic reticulum and/or contractile impairment. ${ }^{10,48-50}$ In our experiments, reduced excitability (ie, plasmalemma electrical dysfunction leading to defective generation and propagation of muscle potential action) largely contributes to the immediate force decrease after lengthening contractions in $m d x$ mice. ${ }^{10}$ Herein, the improved fragility induced by short-term voluntary running in TA muscle by a preserved excitability is explained because CMAP decreased less after lengthening contractions in voluntary runner $m d x$ mice. CsA prevents both the improvements in the force decrease and CMAP decrease after lengthening contractions. Because dystrophin restoration-based gene therapy in $m d x$ mice also reduces the force decrease after lengthening contractions via improved TA muscle excitability, ${ }^{10}$ the results from the present study indicate that voluntary running is effective, as gene therapy.

Another important finding of the present study is that the improved excitability induced by voluntary running was related to the down-regulation of Snc4 and Cacnals, downregulation that was found to be calcineurin pathway dependent (see below). Scn4a and Cacnals encode for the $\alpha$-subunit of NaV1.4 and the principal skeletal muscle $\alpha 1$-dihydropyridine receptor, respectively, which both play an important role in excitability. ${ }^{42}$ Furthermore, because Snc4 and Cacnals are more expressed in fast fibers compared with slow fibers, ${ }^{51,52}$ these results suggest that this difference contributes to the fact that fast muscle is more fragile than slow muscle in $m d x$ mice. ${ }^{7,8}$

\section{Activation of the Calcineurin Pathway Contributes to the Beneficial Effect of Voluntary Exercise}

Numerous studies support the notion that the calcineurin pathway is activated by exercise. ${ }^{23,24,26-28}$ In the present study, the activation of the calcineurin pathway in TA muscle (but not plantaris muscle) is supported by the fact that voluntary running changes the expression of several calcineurin pathway regulator genes (Rcan3, Cmya5, and Myoz 1$)^{40,41}$ and the calcineurin inhibitor CsA blocks the upregulation of Myh2 and Tnnil induced by voluntary running, up-regulation known to be calcineurin pathway dependent. ${ }^{25,43}$

A key finding of the present study is that CsA prevents the improvement in fragility and excitability induced by voluntary running, together with the down-regulation of Scn $4 a$ and Cacnals. Therefore, these results indicate that the mechanism behind the beneficial effect of voluntary 
running is the activation of the calcineurin pathway mediating the down-regulation of Scn $4 a$ and Cacnals in $m d x$ mice. Our conclusion is supported by several studies showing that pharmacologic or genetic calcineurin pathway activation improved dystrophic features, including fragility, in regard to lengthening contractions, in $m d x$ mice. ${ }^{29-31}$ However, it cannot totally be excluded that part of the beneficial effect of voluntary running is not calcineurin dependent because CsA also binds to the mitochondrial protein cyclophilin D. ${ }^{53}$

The beneficial effect of voluntary running mediated by calcineurin pathway activation is related to up-regulation of the slower myofibrillar gene program (ie, Myh2 and Tnnil), encoding for MHC-2a and slow troponin I, respectively. In agreement, it was reported that the longterm voluntary running improvement in fragility of the TA muscle from $m d x$ mice was associated with increased Myh2 expression. ${ }^{20}$ However, the latter study only found a small increase in MHC-2a protein content, suggesting that fragility should not depend on MHC composition per se, but on factors that covary with MHC. ${ }^{20}$ Because $S c n 4 a$ and Cacnals are more expressed in fast fibers compared with slow fibers ${ }^{51,52}$ and voluntary running modulates Scn $4 a$, Cacnals, and Myh2 expression in the TA muscle (the present study), it is suggested that $S c n 4 a$ and Cacnals are the Myh2 covariates.

Several studies show that pharmacologic or genetic activation of signaling pathways, such as calcineurin, peroxisome proliferator-activated receptor- $\beta$, peroxisome proliferator-activated receptor $\gamma$ coactivator $1-\alpha$ (PGC- $1 \alpha)$, and AMP kinase (AMPK), contribute to the promotion of the oxidative gene program and improve fragility in $m d x$ mice..$^{29,33,54-58}$ In the present study, it was found that the beneficial effect of voluntary running is not related to the up-regulation of the oxidative gene program, because CsA prevents the improvement in fragility but not the upregulation of Tfam, Nrfl, and Pgcl- $\beta$, which are important regulators of the oxidative metabolism. ${ }^{21,59}$

Studies from the group of Jasmin ${ }^{29,32,33,54-56}$ support the notion that the beneficial effects of calcineurin pathway activation (and other peroxisome proliferator-activated receptor- $\beta$, PGC- $1 \alpha$, and AMPK pathways) are mediated by increased utrophin A protein level, a substitute for dystrophin. ${ }^{35-37}$ For example, the beneficial effects of pharmacologic activation of the pathway-promoting oxidative gene program are absent in $m d x$ mice with utrophin deficiency. ${ }^{56}$ Herein, it was reported that the improved fragility induced by voluntary running is not related to increased utrophin A protein level. Likely, the duration of 1 week of voluntary running was not enough to increase utrophin A protein levels in $m d x$ mice. $^{60}$

On the basis of the present study, it is suggested that a contributing underlying mechanism of the improvement of fragility induced by voluntary running is activation of the calcineurin pathway, promoting a covariate of the slow myofibrillar gene program, involved in the excitability gene program (coding for sarcolemmal channels and pumps), but not the oxidative gene program and utrophin.

\section{Conclusions}

Our results indicate that the short-term voluntary running-induced improvement in fragility in dystrophic $m d x$ muscle was explained by preserved excitability. Moreover, they strongly suggest that activation of the calcineurin pathway contributes to the beneficial effect of voluntary running. These results also suggest that calcineurin pathway activation contributes to improved fragility and preserved excitability via the up-regulation of the slow gene program, including the down-regulation of Scn4a and Cacnals, but not the promotion of the oxidative gene program and utrophin up-regulation. It will be interesting to repeat these studies in more severe animal models of DMD, to confirm the fact that voluntary running improves fragility, supporting the concept that appropriate chronic exercise could be a possible therapeutic strategy in DMD patients, by decreasing the occurrence of degeneration-regeneration cycles that contribute to progressive muscle weakness and loss. Moreover, the present study indicates that preservation of excitability might represent a promising target for the treatment of DMD because inactivity increases muscle weakness and fragility in dystrophic muscle. ${ }^{20}$

\section{Acknowledgments}

We thank Pierre Joanne and Christel Gentil for assistance during the experiments.

\section{References}

1. Chan S, Head SI: The role of branched fibres in the pathogenesis of Duchenne muscular dystrophy. Exp Physiol 2011, 96:564-571

2. Gumerson JD, Michele DE: The dystrophin-glycoprotein complex in the prevention of muscle damage. J Biomed Biotechnol 2011, 2011: 210797

3. Lynch GS: Role of contraction-induced injury in the mechanisms of muscle damage in muscular dystrophy. Clin Exp Pharmacol Physiol 2004, 31:557-561

4. Dellorusso C, Crawford RW, Chamberlain JS, Brooks SV: Tibialis anterior muscles in mdx mice are highly susceptible to contractioninduced injury. J Muscle Res Cell Motil 2001, 22:467-475

5. Hayes A, Williams DA: Beneficial effects of voluntary wheel running on the properties of dystrophic mouse muscle. J Appl Phys 1996, 80: 670-679

6. Pastoret C, Sebille A: Time course study of the isometric contractile properties of mdx mouse striated muscles. J Muscle Res Cell Motil 1993, 14:423-431

7. Head SI, Williams DA, Stephenson DG: Abnormalities in structure and function of limb skeletal muscle fibres of dystrophic mdx mice. Proc Biol Sci 1992, 248:163-169

8. Moens P, Baatsen PH, Marechal G: Increased susceptibility of EDL muscles from mdx mice to damage induced by contractions with stretch. J Muscle Res Cell Motil 1993, 14:446-451 
9. Petrof BJ, Shrager JB, Stedman HH, Kelly AM, Sweeney HL: Dystrophin protects the sarcolemma from stresses developed during muscle contraction. Proc Natl Acad Sci U S A 1993, 90:3710-3714

10. Roy P, Rau F, Ochala J, Messéant J, Fraysse B, Lainé J, Agbulut O, Butler-Browne G, Furling D, Ferry A: Dystrophin restoration therapy improves both the reduced excitability and the force drop induced by lengthening contractions in dystrophic mdx skeletal muscle. Skelet Muscle 2016, 6:23

11. Dumonceaux J, Marie S, Beley C, Trollet C, Vignaud A, Ferry A, Butler-Browne G, Garcia L: Combination of myostatin pathway interference and dystrophin rescue enhances tetanic and specific force in dystrophic mdx mice. Mol Ther 2010, 18:881-887

12. Goyenvalle A, Griffith G, Babbs A, El Andaloussi S, Ezzat K, Avril A, Dugovic B, Chaussenot R, Ferry A, Voit T, Amthor H, Buhr C, Schurch S, Wood MJ, Davies KE, Vaillend C, Leumann C, Garcia L: Functional correction in mouse models of muscular dystrophy using exon-skipping tricyclo-DNA oligomers. Nat Med 2015, $21: 270-275$

13. Hoogaars W, Mouisel E, Pasternack A, Hulmi JJ, Relizani K, Schuelke M, Schirwis E, Garcia L, Ritvos O, Ferry A, t Hoen PA, Amthor H: Combined effect of AAV-U7-induced dystrophin exon skipping and soluble activin type IIB receptor in mdx mice. Hum Gene Ther 2012, 23:1269-1279

14. Koo T, Malerba A, Athanasopoulos T, Trollet C, Boldrin L, Ferry A, Popplewell L, Foster H, Foster K, Dickson G: Delivery of AAV2/9microdystrophin genes incorporating helix 1 of the coiled-coil motif in the C-terminal domain of dystrophin improves muscle pathology and restores the level of alpha1-syntrophin and alpha-dystrobrevin in skeletal muscles of mdx mice. Hum Gene Ther 2011, 22:1379-1388

15. Hyzewicz J, Ruegg UT, Takeda S: Comparison of experimental protocols of physical exercise for mdx mice and Duchenne muscular dystrophy patients. J Neuromuscul Dis 2015, 2:325-342

16. Lovering RM, Brooks SV: Eccentric exercise in aging and diseased skeletal muscle: good or bad? J Appl Physiol (1985) 2014, 116: $1439-1445$

17. Call JA, Voelker KA, Wolff AV, McMillan RP, Evans NP, Hulver MW, Talmadge RJ, Grange RW: Endurance capacity in maturing mdx mice is markedly enhanced by combined voluntary wheel running and green tea extract. J Appl Physiol (1985) 2008, 105:923-932

18. Call JA, McKeehen JN, Novotny SA, Lowe DA: Progressive resistance voluntary wheel running in the $\mathrm{mdx}$ mouse. Muscle Nerve 2010, 42:871-880

19. Selsby JT, Acosta P, Sleeper MM, Barton ER, Sweeney HL: Longterm wheel running compromises diaphragm function but improves cardiac and plantarflexor function in the mdx mouse. J Appl Physiol (1985) 2013, 115:660-666

20. Hourde C, Joanne P, Medja F, Mougenot N, Jacquet A, Mouisel E, Pannerec A, Hatem S, Butler-Browne G, Agbulut O, Ferry A: Voluntary physical activity protects from susceptibility to skeletal muscle contraction-induced injury but worsens heart function in $\mathrm{mdx}$ mice. Am J Pathol 2013, 182:1509-1518

21. Booth FW, Ruegsegger GN, Toedebusch RG, Yan Z: Endurance exercise and the regulation of skeletal muscle metabolism. Prog Mol Biol Transl Sci 2015, 135:129-151

22. Gundersen K: Excitation-transcription coupling in skeletal muscle: the molecular pathways of exercise. Biol Rev Camb Philos Soc 2010, $86: 564-600$

23. Schiaffino S, Sandri M, Murgia M: Activity-dependent signaling pathways controlling muscle diversity and plasticity. Physiology (Bethesda) 2007, 22:269-278

24. Yan Z, Okutsu M, Akhtar YN, Lira VA: Regulation of exerciseinduced fiber type transformation, mitochondrial biogenesis, and angiogenesis in skeletal muscle. J Appl Physiol (1985) 2011, 110: 264-274

25. Chin ER, Olson EN, Richardson JA, Yang Q, Humphries C, Shelton JM, Wu H, Zhu W, Bassel-Duby R, Williams RS: A calcineurin-dependent transcriptional pathway controls skeletal muscle fiber type. Genes Dev 1998, 12:2499-2509

26. Dunn SE, Burns JL, Michel RN: Calcineurin is required for skeletal muscle hypertrophy. J Biol Chem 1999, 274:21908-21912

27. Pandorf CE, Jiang WH, Qin AX, Bodell PW, Baldwin KM, Haddad F: Calcineurin plays a modulatory role in loading-induced regulation of type I myosin heavy chain gene expression in slow skeletal muscle. Am J Physiol Regul Integr Comp Physiol 2009, 297: R1037-R1048

28. Parsons SA, Millay DP, Wilkins BJ, Bueno OF, Tsika GL, Neilson JR, Liberatore CM, Yutzey KE, Crabtree GR, Tsika RW, Molkentin JD: Genetic loss of calcineurin blocks mechanical overload-induced skeletal muscle fiber type switching but not hypertrophy. J Biol Chem 2004, 279:26192-26200

29. Chakkalakal JV, Michel SA, Chin ER, Michel RN, Jasmin BJ: Targeted inhibition of $\mathrm{Ca} 2+/$ calmodulin signaling exacerbates the dystrophic phenotype in mdx mouse muscle. Hum Mol Genet 2006, 15:1423-1435

30. Stupka N, Plant DR, Schertzer JD, Emerson TM, Bassel-Duby R, Olson EN, Lynch GS: Activated calcineurin ameliorates contractioninduced injury to skeletal muscles of mdx dystrophic mice. J Physiol 2006, 575:645-656

31. Stupka N, Schertzer JD, Bassel-Duby R, Olson EN, Lynch GS: Stimulation of calcineurin Aalpha activity attenuates muscle pathophysiology in mdx dystrophic mice. Am J Physiol Regul Integr Comp Physiol 2008, 294:R983-R992

32. Chakkalakal JV, Harrison M-A, Carbonetto S, Chin E, Michel RN, Jasmin BJ: Stimulation of calcineurin signaling attenuates the dystrophic pathology in mdx mice. Hum Mol Genet 2004, 13: 379-388

33. Chakkalakal JV, Stocksley MA, Harrison MA, Angus LM, Deschenes-Furry J, St-Pierre S, Megeney LA, Chin ER, Michel RN, Jasmin BJ: Expression of utrophin A mRNA correlates with the oxidative capacity of skeletal muscle fiber types and is regulated by calcineurin/NFAT signaling. Proc Natl Acad Sci U S A 2003, 100: $7791-7796$

34. Banks GB, Combs AC, Odom GL, Bloch RJ, Chamberlain JS: Muscle structure influences utrophin expression in mdx mice. PLoS Genet 2014, 10:e1004431

35. Deconinck N, Rafael JA, Beckers-Bleukx G, Kahn D, Deconinck AE, Davies KE, Gillis JM: Consequences of the combined deficiency in dystrophin and utrophin on the mechanical properties and myosin composition of some limb and respiratory muscles of the mouse. Neuromuscul Disord 1998, 8:362-370

36. Deconinck N, Tinsley J, De Backer F, Fisher R, Kahn D, Phelps S, Davies K, Gillis JM: Expression of truncated utrophin leads to major functional improvements in dystrophin-deficient muscles of mice. Nat Med 1997, 3:1216-1221

37. Squire S, Raymackers JM, Vandebrouck C, Potter A, Tinsley J, Fisher R, Gillis JM, Davies KE: Prevention of pathology in mdx mice by expression of utrophin: analysis using an inducible transgenic expression system. Hum Mol Genet 2002, 11:3333-3344

38. Ferry A, Parlakian A, Joanne P, Fraysse B, Mgrditchian T, Roy P, Furling D, Butler-Browne G, Agbulut O: Mechanical overloading increases maximal force and reduces fragility in hind limb skeletal muscle from Mdx mouse. Am J Pathol 2015, 185: $2012-2024$

39. Ferry A, Joanne P, Hadj-Said W, Vignaud A, Lilienbaum A, Hourdé C, Medja F, Noirez P, Charbonnier F, Chatonnet A, Chevessier F, Nicole S, Agbulut O, Butler-Browne G: Advances in the understanding of skeletal muscle weakness in murine models of diseases affecting nerve-evoked muscle activity, motor neurons, synapses and myofibers. Neuromuscul Disord 2014, 24:960-972

40. Frey N, Frank D, Lippl S, Kuhn C, Kögler H, Barrientos T, Rohr C, Will R, Müller OJ, Weiler H, Bassel-Duby R, Katus HA, Olson EN: Calsarcin-2 deficiency increases exercise capacity in mice through calcineurin/NFAT activation. J Clin Invest 2008, 118:3598-3608 
41. Kivelä R, Salmela I, Nguyen YH, Petrova TV, Koistinen HA, Wiener Z, Alitalo K: The transcription factor Prox1 is essential for satellite cell differentiation and muscle fibre-type regulation. Nat Commun 2016, 7:13124

42. Cannon SC: Channelopathies of skeletal muscle excitability. Compr Physiol 2015, 5:761-790

43. Talmadge RJ, Otis JS, Rittler MR, Garcia ND, Spencer SR, Lees SJ, Naya FJ: Calcineurin activation influences muscle phenotype in a muscle-specific fashion. BMC Cell Biol 2004, 5:28

44. Ferry A, Benchaouir R, Joanne P, Peat RA, Mougenot N, Agbulut O, Butler-Browne G: Effect of voluntary physical activity initiated at age 7 months on skeletal hindlimb and cardiac muscle function in $\mathrm{mdx}$ mice of both genders. Muscle Nerve 2015, 52:788-794

45. Capogrosso RF, Mantuano P, Cozzoli A, Sanarica F, Massari AM, Conte E, Fonzino A, Giustino A, Rolland J-F, Quaranta A, De Bellis M, Camerino GM, Grange RW, De Luca A: Contractile efficiency of dystrophic mdx mouse muscle: in vivo and ex vivo assessment of adaptation to exercise of functional end points. J Appl Physiol (1985) 2017, 122:828-843

46. Zhang Y, Yue Y, Li L, Hakim CH, Zhang K, Thomas GD, Duan D: Dual AAV therapy ameliorates exercise-induced muscle injury and functional ischemia in murine models of Duchenne muscular dystrophy. Hum Mol Genet 2013, 22:3720-3729

47. Sacco A, Mourkioti F, Tran R, Choi J, Llewellyn M, Kraft P, Shkreli M, Delp S, Pomerantz JH, Artandi SE, Blau HM: Short telomeres and stem cell exhaustion model Duchenne muscular dystrophy in mdx/mTR mice. Cell 2010, 143:1059-1071

48. Blaauw B, Agatea L, Toniolo L, Canato M, Quarta M, Dyar KA, Danieli-Betto D, Betto R, Schiaffino S, Reggiani C: Eccentric contractions lead to myofibrillar dysfunction in muscular dystrophy. J Appl Physiol (1985) 2010, 108:105-111

49. Call JA, Warren GL, Verma M, Lowe DA: Acute failure of action potential conduction in mdx muscle reveals new mechanism of contraction-induced force loss. J Physiol 2013, 591:3765-3776

50. Pratt SJ, Shah SB, Ward CW, Inacio MP, Stains JP, Lovering RM: Effects of in vivo injury on the neuromuscular junction in healthy and dystrophic muscles. J Physiol 2013, 591:559-570

51. Lucas B, Ammar T, Khogali S, DeJong D, Barbalinardo M, Nishi C, Hayward LJ, Renaud J-M: Contractile abnormalities of mouse muscles expressing hyperkalemic periodic paralysis mutant NaV1.4 channels do not correlate with $\mathrm{Na}+$ influx or channel content. Physiol Genomics 2014, 46:385-397

52. Mänttäri S, Ørtenblad N, Madsen K, Pilegaard H: Both short intense and prolonged moderate in vitro stimulation reduce the mRNA expression of calcium-regulatory proteins in rat skeletal muscle. Mol Cell Biochem 2013, 373:171-178

53. Irwin WA, Bergamin N, Sabatelli P, Reggiani C, Megighian A, Merlini L, Braghetta P, Columbaro M, Volpin D, Bressan GM, Bernardi P, Bonaldo P: Mitochondrial dysfunction and apoptosis in myopathic mice with collagen VI deficiency. Nat Genet 2003, 35: $367-371$

54. Ljubicic V, Miura P, Burt M, Boudreault L, Khogali S, Lunde JA, Renaud JM, Jasmin BJ: Chronic AMPK activation evokes the slow, oxidative myogenic program and triggers beneficial adaptations in mdx mouse skeletal muscle. Hum Mol Genet 2011, 20:3478-3493

55. Miura P, Chakkalakal JV, Boudreault L, Belanger G, Hebert RL, Renaud JM, Jasmin BJ: Pharmacological activation of PPARbeta/delta stimulates utrophin A expression in skeletal muscle fibers and restores sarcolemmal integrity in mature mdx mice. Hum Mol Genet 2009, 18:4640-4649

56. Al-Rewashdy H, Ljubicic V, Lin W, Renaud J-M, Jasmin BJ: Utrophin $\mathrm{A}$ is essential in mediating the functional adaptations of $\mathrm{mdx}$ mouse muscle following chronic AMPK activation. Hum Mol Genet 2015, 24:1243-1255

57. Matsakas A, Yadav V, Lorca S, Narkar V: Muscle ERR $\gamma$ mitigates Duchenne muscular dystrophy via metabolic and angiogenic reprogramming. FASEB J 2013, 27:4004-4016

58. Chan MC, Rowe GC, Raghuram S, Patten IS, Farrell C, Arany Z: Post-natal induction of $\mathrm{PGC}-1 \alpha$ protects against severe muscle dystrophy independently of utrophin. Skelet Muscle 2014, 4:2

59. Gali Ramamoorthy T, Laverny G, Schlagowski A-I, Zoll J, Messaddeq N, Bornert J-M, Panza S, Ferry A, Geny B, Metzger D: The transcriptional coregulator PGC-1 $\beta$ controls mitochondrial function and anti-oxidant defence in skeletal muscles. Nat Commun $2015,6: 10210$

60. Gordon BS, Lowe DA, Kostek MC: Exercise increases utrophin protein expression in the mdx mouse model of Duchenne muscular dystrophy. Muscle Nerve 2014, 49:915-918 